\title{
A Comparative Analysis of FISH, RT-PCR, PCR, and Immunohistochemistry for the Diagnosis of Mantle Cell Lymphomas
}

\author{
Marc-Antoine Belaud-Rotureau, Ph.D., Marie Parrens, M.D., Pierre Dubus, M.D., Ph.D., \\ Jean-Christophe Garroste, Antoine de Mascarel, M.D., Jean-Philippe Merlio, M.D., Ph.D. \\ Department of Histology and Molecular Pathology, Victor Segalen University ( $M-A B-R, M P, P D, A d M, J-$ \\ $P M)$, Bordeaux, France and Pathology Laboratory, Hôpital Haut-Léveque (M-AB-R, MP, PD, J-CG, AdM, \\ J-PM), Pessac, France
}

Mantle cell lymphoma (MCL) diagnosis first relies on morphology and phenotype that may overlap with other B-cell lymphomas. Therefore, the demonstration of $t(11 ; 14)(q 13 ; q 32)$, the cytogenetic hallmark of MCL, is considered of diagnostic value. By studying a series of 35 MCL with characteristic morphology and phenotype (CD5+, CD10-, CD20+, CD23-), we have evaluated the applicability and the sensitivity of interphase fluorescence in situ hybridization (FISH) for $t(11 ; 14)$ detection and other techniques: (1) polymerase chain reaction $(\mathrm{PCR})$ for amplification of $t(11 ; 14)$ genomic breakpoint, (2) competitive RT-PCR for the detection of cyclin D1 transcripts overexpression, and (3) immunohistochemistry (IHC) for cyclin D1 protein detection. Tissues from different origins were analyzed: lymph nodes $(n=24)$, spleen $(n=3)$, digestive biopsy $(n=$ $3)$, tonsils $(n=3)$, and skin $(n=2)$. Interphase FISH was performed either on touch preparations $(n=$ $11)$ and frozen $(n=9)$ or paraffin sections $(n=15)$. FISH analysis detected $t(11 ; 14)$ in $34 / 35$ cases $(97 \%)$ and demonstrated a recurrent $C C N D 1$ amplification in $t(11 ; 14)+$ nuclei of the three blastoid MCL variants of our series. Genomic PCR analysis, hampered by the scattering of 11 q13 breakpoints, was positive in only $13 / 35$ cases (37\%). RT-PCR analysis was applicable on nonepithelial tissues $(27 / 35)$ and showed cyclin D1 transcript overexpression in all tested cases (27/35). IHC for cyclin D1 protein was performed either on frozen $(n=12)$ or on paraffin

Copyright () 2002 by The United States and Canadian Academy of Pathology, Inc.

VOL. 15, NO. 5, P. 517, 2002 Printed in the U.S.A.

Date of acceptance: December 20, 2001

This work was supported by grants from the Region Aquitaine and the Ligue contre le Cancer (Comité de la Gironde) and the Program Hospitalier de Recherche Clinique.

Address reprint requests to: Marc-Antoine Belaud-Rotureau, Ph.D., EA 2406 Histologie et Pathologie Moléculaire, Université Victor Segalen, 146 rue Léo Saignat, 33076 Bordeaux, Cedex, France; e-mail: jp.merlio@histo.u-bordeaux2.fr; fax: 33-0-5-5757-1032. sections $(n=23)$, and its sensitivity was higher on paraffin sections $(91 \%)$ than on frozen sections (25\%). A cyclin D1 protein immunoreactivity was observed in $24 / 35$ cases (69\%). Our study emphasizes on the use of FISH analysis for the direct detection of $t(11 ; 14)$ because its applicability and sensitivity largely exceeded those of other techniques. It may also provide some informations on secondary cytogenetic changes of potential clinical relevance.

KEY WORDS: CCND1, Cyclin D1, FISH, Mantle cell lymphoma, PCR, RT-PCR, t(11;14)(q13;q32).

Mod Pathol 2002;15(5):517-525

Mantle cell lymphoma (MCL), previously recognized as centrocytic lymphoma, represents 3 to $9 \%$ of all non-Hodgkin lymphomas in Western countries (1). It has been individualized both in the REAL and in the World Health Organization classifications because it represents a distinct clinical pathological entity with a special aggressive course among small B-cell lymphomas $(2,3)$. It frequently involves lymph node, blood, bone marrow, and spleen $(4,5)$. The neoplastic cells typically exhibit a centrocytic morphology and coexpress pan-B-cell markers CD5 and CD43 but lack CD23 and CD10. They are surface IgM and often IgD positive (2). Despite these characteristics, MCL may be difficult to differentiate from other small B-cell lymphoma, especially at extranodal sites, or when the typical morphologic and phenotypic profile of MCL cannot be demonstrated (6-8).

The $\mathrm{t}(11 ; 14)(\mathrm{q} 13 ; \mathrm{q} 32)$ has been identified as a recurrent and characteristic feature of MCL (9-11). This translocation juxtaposes an immunoglobulin heavy chain gene $(I G H)$ transcriptional enhancer on chromosome 14q32 to the proto-oncogene CCND1 (bcl-1, $P R A D 1)$ encoding cyclin D1 on chromosome 11q13 (12-15). It results in the overexpression of cyclin D1 messenger RNA $(10,15-17)$ and protein $(18,19)$. Cyclin D1 belongs to the G1 cyclins and plays a key role 
in the cell cycle regulation during the G1/S transition (20). A variant translocation implying $C C N D 1$ and $I G$ light chain loci has been described in only one case of MCL (21), and nearly all MCL exhibit the translocation $(11 ; 14)(q 13 ; q 32)$ (22). The breakpoint on chromosome 11q13 covers a wide range distance from the CCND1 gene, between 15 and $>400 \mathrm{~kb}(10,14,23)$. Beside Southern blot for the demonstration of $b c l-1$ rearrangement that requires a large amount of genomic DNA, polymerase chain reaction (PCR) can achieve amplification of $\mathrm{t}(11 ; 14)$ breakpoints in only 35 to $60 \%$ of cases (24-26). Karyotype analysis allowed identification of $\mathrm{t}(11 ; 14)$ (q13;q32) in only 70 to $75 \%$ of MCL, which may be related to the low mitotic index of malignant cells and to the poor morphology of metaphase spreads $(9,27)$. Interphase fluorescence in situ hybridization (FISH) analysis circumvents these difficulties and has allowed the detection of $\mathrm{t}(11 ; 14)$ in nearly $100 \%$ of MCL cases $(8,28,29)$. Moreover, detection of $\mathrm{t}(11 ; 14)$ by interphase FISH was achieved on cell suspensions or on nuclei isolated from fresh-frozen or paraffin-embedded material (8, 29). Competitive or semi-quantitative reverse transcriptase polymerase chain reaction (RT-PCR) allowed to detection of cyclin D1 transcript overexpression in nearly all MCL cases $(7,16)$. Cyclin D1 protein can also be detected at the level of tumor cells by immunohistochemistry (IHC), with a range of positivity between 69 and $100 \%(4,6,7,18)$. By comparing the specificity of each technique between MCL and other small B-cell lymphoproliferative disorders, several studies also showed that none of the above criteria could be undertaken in isolation for diagnostic purpose (30). Indeed, $t(11 ; 14)$ has been identified by karyotype analysis or FISH in a wide variety of B-cell malignancies such as splenic lymphoma with villous lymphocytes, B-cell prolymphocytic leukemia, and multiple myeloma $(10,31)$. Moreover, cyclin D1 mRNA was detected in significant subsets of nonMCL and in some atypical lymphoid hyperplasia (4, 7). Cyclin D1 immunoreactivity may be difficult to detect in typical MCL cases and may also be present in hairy cell leukemia or other low-grade B-cell neoplasms (32).

However, no combined study of $\mathrm{t}(11 ; 14)$ by cytogenetic (FISH or karyotype) or molecular (PCR and RT-PCR) techniques and of cyclin D1 IHC has been undertaken to evaluate the sensitivity (positive cases/total cases) and the applicability (analyzed cases/total cases) of each technique in MCL diagnosis. In this aim, we retrieved from our files $35 \mathrm{MCL}$ cases on the basis of typical morphological and phenotypic features. In addition, we employed an original interphase FISH technique on paraffinembedded sections. The results of each technique were compared to allow us to propose FISH as the method of choice for demonstration of $t(11 ; 14)$ on routine pathologic specimens.

\section{PATIENTS AND METHODS}

\section{Patients}

The study included 35 patients with MCL de novo or in relapse, as classified according to the World Health Organization (3). The inclusion criteria were typical morphology and immunophenotype (CD20+, CD5+, CD10-, CD23-). Tissues from different origin were analyzed: lymph nodes (24), spleen (3), digestive biopsy (3), tonsils (3), skin (2). Touch preparations (11) or $5-\mu \mathrm{m}$ sections (9) were performed from frozen tissues, and $2-3-\mu \mathrm{m}$ sections (15) were done from formalin-fixed paraffinembedded tissues.

\section{PCR and RT-PCR Analyses}

For PCR analysis, DNA was extracted from frozen and formalin-fixed, paraffin-embedded sections according to a standard procedure. The analysis of $t(11 ; 14)$ was performed as previously described (25), using primer pair MCL1 (5'-GATGGGCTTCTCTCACCTACTA-3' and JH (5'-ACCTGAGGAGACGGTGACCAGGGT-3'). Five hundred nanograms of genomic DNA were amplified on an automated thermal cycler (Hybaid Limited, Teddington, UK) in a final volume of $50 \mu \mathrm{L}$, with $1.5 \mathrm{U}$ of Taq polymerase (Promega, Madison, WI), $1 \times$ buffer (Promega), $1.5 \mathrm{~mm} \mathrm{MgCl}_{2}, 200 \mu \mathrm{M}$ of each deoxynucleotide triphosphate, and 50 pmol of primers MCL1 and $\mathrm{JH}$. After an initial step at $94^{\circ} \mathrm{C}$ for 5 minutes, 35 cycles were performed, each cycle consisting of denaturation at $94^{\circ} \mathrm{C}$ for 1 minute, annealing at $55^{\circ} \mathrm{C}$ for 1 minute, and elongation at $72^{\circ} \mathrm{C}$ for 1 minute. Amplicons were electrophoresed on a $1 \%$ agarose gel, stained with ethidium bromide, then blotted onto nylon membranes (Hybond $\mathrm{N}+$; Amersham International, Buckinghamshire, UK). After prehybridization, membranes were hybridized at $42^{\circ} \mathrm{C}$ overnight in a solution of $5 \times$ standard saline citrate (SSC), $5 \times$ Denhardt's solution, $0.5 \%$ sodium dodecyl sulfate, $0.2 \mathrm{~g} / \mathrm{L}$ salmon testes sonicated denatured DNA (Sigma, St Louis, MO), and 10 pmol of the $5^{\prime}$ digoxigenin-labeled MCL2 internal primer probe 5'-TCAGGCCTTGATAGCTCG - 3'. Blots were washed twice in $2 \times$ SSC, $0.1 \%$ sodium dodecyl sulfate for 15 minutes at room temperature, then twice in $1 \times$ SSC, $0.1 \%$ sodium dodecyl sulfate for 20 minutes at $55^{\circ} \mathrm{C}$. Membranes were equilibrated for 1 minute in Buffer 1 (0.1 м Maleic Acid, 0.15 M NaCl, $0.3 \%$ Tween 20), incubated 40 minutes with 10\% Blocking Reagent (Roche Diagnostics, Meylan, France) in Buffer 1, and then 30 minutes with $10 \mu \mathrm{L}$ anti-digoxigenin alkaline phosphatase-conjugated antibody (Roche Diagnostics) in 10\% Blocking Reagent/Buffer 1. Blots were washed twice in Buffer 1 for 15 minutes at room temperature, equilibrated in $0.1 \mathrm{M} \mathrm{NaCl}, 0.1 \mathrm{M}$ Tris-HCl, $\mathrm{pH} 9.5$, for $2 \mathrm{~min}$ utes then covered with $1 \mathrm{~mL}$ of 1/500 CSPD (Roche Diagnostics) in $0.1 \mathrm{~m}$ Tris- $\mathrm{HCl}$ and $0.1 \mathrm{M} \mathrm{NaCl}, \mathrm{pH}$ 9.5, sealed in a plastic bag, and incubated for 15 minutes at 
$37^{\circ} \mathrm{C}$. Blots were exposed to an x-ray film for 16 hours (Kodak X-Omat, Rochester, NY). Negative (reaction mixture without template) and positive (DNA extracted from REC-1 cells kindly provided by Dr. T. Al Saati, CHU Purpan, Toulouse, France) controls were included in each experiment.

The detection of cyclin D1 overexpression by competitive RT-PCR was performed as previously described (16) with only slight modifications. Briefly, $10 \mathrm{mg}$ of frozen tissues was homogenized in a $1.5-\mathrm{mL}$ tube with a sterile piston in $1 \mathrm{~mL}$ of Trizol reagent (Life Technologies, Cergy-Pontoise, France), and total RNA was extracted according to the manufacturer's instructions. Four microgram of total RNA was incubated with $20 \mathrm{U}$ of RNAse-free DNAse I and then reverse transcribed into cDNA using $800 \mathrm{ng}$ of hexamers (pDN6, Roche Diagnostics) and $200 \mathrm{U}$ of Superscript reverse transcriptase (Life Technologies). The cDNA $(2 \mu \mathrm{L})$ was amplified on an automated thermal cycler (Hybaid Limited) in a final volume of $50 \mu \mathrm{L}$ with $1.5 \mathrm{U}$ of Taq polymerase (Promega, Madison, WI), $1 \times$ buffer (Promega), $1.5 \mathrm{~mm}$ of $\mathrm{MgCl}_{2}, 200 \mu \mathrm{M}$ of each deoxynucleotide triphosphate, and 50 pmol of primers D1S385, D1AS867, D2ASS609, and D3AS649. All primers were preheated for 2 minutes at $95^{\circ} \mathrm{C}$ before their addition to the reaction mix. The D1S385 upstream primer (5'-CTGGCCATGAACTACCTGGA-3') is consensus for all three cyclin D sequences, whereas D1AS867 (5'-GTCACACTTGATCACTCTGG-3'), D2ASS609 (5'-CATGGCAAACTTAAAGTCGG) and D3AS649 (5'-CCAGGAAATCATGTGCAATC-3') primers are specific for cyclin D1, D2, and D3, respectively. After an initial step at $94^{\circ} \mathrm{C}$ for 5 minutes, 35 cycles were performed, each cycle consisting of denaturation at $94^{\circ} \mathrm{C}$ for 1 minute, annealing at $51^{\circ} \mathrm{C}$ for 1 minute, and elongation at $72^{\circ} \mathrm{C}$ for 1 minute. RTPCR amplicons $(10 \mu \mathrm{L})$ were electrophoresed on a $2 \%$ agarose gel, stained with ethidium bromide, and photographed under ultraviolet light. Cyclin D1 transcripts were considered overexpressed when the intensity of the 482-bp cyclin D1 band was found to be higher than the sum of two other bands (353 bp for cyclin D2 and 243 bp for cyclin D3). Negative controls (reaction mixture without template and cDNA from a follicular lymphoma) were included in each PCR set.

\section{FISH Analysis}

The $\mathrm{t}(11 ; 14)(\mathrm{q} 13 ; \mathrm{q} 32)$ was detected in a dual-color FISH analysis using the previously described IGHCCND1 probe set (Adgenix, Voisins Le Bretonneux, France; 8). Briefly, this reciprocal translocation implied the juxtaposition of directly labeled IGH (spectrum green) and CCND1 (spectrum orange), probes resulting in two yellow fusion signals $(\mathrm{F}$, der (11) and der (14)) in addition to one red ( $\mathrm{R}$, chromosome 11) and one green $(\mathrm{G}$, chromosome 14) signals. Thus, the usual FISH pattern was 2R2G in normal nuclei and $1 R 1 G 2 F$ in $t(11 ; 14)$ nuclei. Other patterns have been described by Remstein et al. (8) in normal and $t(11 ; 14)$ nuclei. For example, the pattern was sometimes $1 \mathrm{R} 1 \mathrm{G} 1 \mathrm{~F}$ in normal nuclei when one red and one green signal were juxtaposed by chance or $2 \mathrm{R} 2 \mathrm{G} 1 \mathrm{~F}$ in $\mathrm{t}(11$; 14) nuclei when one red and one green signal were simply juxtaposed without fusion (8). All these previously described FISH patterns were considered for the exact determination of the percentage of normal and $t(11 ; 14)$ nuclei in our study. Touch preparations, cytospins and frozen sections $(5 \mu \mathrm{m})$ were fixed by immersion in $100 \%$ methanol ( $5 \mathrm{~min}$, room temperature) and in Carnoy (methanol 0.75, acetic acid 0.25, $30 \mathrm{~min}, 4^{\circ} \mathrm{C}$ ). Slides were air-dried and placed for 1 hour in a $37^{\circ} \mathrm{C}$ incubator before dehydration (ethanol at $70,80,90$, and $100 \%$ for 2 min each, room temperature). After air-drying, probes $(10 \mu \mathrm{L})$ were added to each slide according to the manufacturer's instructions, and a $22 \times 22-\mathrm{mm}$ coverslip was placed over each hybridization slide and sealed with rubber cement. Slides and probes were codenatured $\left(85^{\circ} \mathrm{C}, 1\right.$ min) using the Vysis Hybrite Hybridization System (Adgenix), and hybridization was performed for 24 hours at $37^{\circ} \mathrm{C}$ in a humidified box. Then, slides were rapidly washed and dehydrated and nuclei were counterstained as previously described (8). Paraffinembedded tissue sections $(2-3 \mu \mathrm{m})$ were deparaffinized by warming for 1 hour at $65^{\circ} \mathrm{C}$ and by xylene immersion ( $15 \mathrm{~min}$, room temperature). After dehydration, they were placed in a $\mathrm{HCl}$ bath $(0.2 \mathrm{~N}, 20 \mathrm{~min}$, room temperature) and treated by the Vysis paraffin pretreatment kit (Adgenix) according to the manufacturer's instructions. Then, slides were dehydrated and air-dried and probe $(10 \mu \mathrm{l})$ was added. Codenaturation was performed in the Hybrite at $85^{\circ} \mathrm{C}$ during 3 minutes. The end of the protocol was the same as before. Cells were viewed using a fluorescent microscope (Zeiss, Le Pecq, France) with appropriate filters. The FISH patterns were interpreted after three counts of 300 nuclei. Briefly, a specimen was classified as abnormal and consistent with IGH-CCNDI fusion if the number of nuclei observed with $t(11 ; 14)$ patterns was $>5 \%$ (8). This threshold was found after the analysis of five control lymph nodes (reactive lymphadenitis). As previously described, it was the mean $+3 \mathrm{SD}$ of the percentage of nuclei with a $t(11 ; 14)$ FISH pattern in control samples (8).

\section{Immunochemistry for Cyclin D1}

IHC for Cyclin D1 was performed in 23 cases on $10 \%$ formalin-fixed paraffin-embedded sections. In 12 cases, with Bouin's liquid as fixative for paraffinembedded material, formalin-postfixed frozen sections were used for cyclin D1 IHC. The analysis was realized on an automated Chemate (DAKO, les Ul- 
lis, France) using the monoclonal anti-Cyclin D1 antibody (P2D11F11, Novocastra, Tebu, Le Perrayen-Yvelines, France) and the biotin-streptavidinperoxidase LSAB kit. Before immunostaining, antigenunmasking procedure was performed by 10 minutes of pressure-cooker boiling in Target retrieval solution at a high $\mathrm{pH}$ (DAKO). Two reviewers (MP, JPM) categorized independently the intensity of nuclear labeling as low $(+)$, moderate $(++)$, and strong $(+++)$ and the number of cells with nuclear staining (more or less than $50 \%$ cells). Cytoplasmic staining was not considered specific and was also observed in histiocytes and endothelial cells $(6,7)$. Except when a nuclear labeling of epithelial cell was present on epithelial specimens, no reliable internal positive control of the cyclin D1 staining was available on lymphoid tissues. Therefore, nonpositive cases were classified as negative or noncontributive $(\mathrm{N})$.

\section{RESULTS}

The study included 35 MCL. Morphological analysis showed either a monotonous proliferation of small to medium-sized lymphocytes with irregular nuclei and relatively low proliferate activity (32/35, centrocytoid variant, Fig. 1A, C) or larger cells with more cytoplasm, round to oval nuclei with coarsely dispersed chromatin, and occasional nucleoli (3/35, blastoid variant, Fig. 1J). Malignant cells (CD20+, CD10-) expressed CD5 (Fig. 1D) and were CD23 negative (Fig. 1B). Cyclin D1 protein immunoreactivity was detected by IHC in $24 / 35$ MCL/(Table 1 ). The labeling intensity was evaluated by both reviewers as low $(+, 2 / 35$, Figs. $1 \mathrm{E}$ and 2$)$, medium $(++, 10 / 35$, Fig. 2$)$, or high $(+++, 12 / 35$, Figs. 1F and 2 ). This intensity paralleled the percentage of positive cells and was +++ for cases with $>50 \%$ of positive cells (Fig. 2). Cyclin D1 IHC was positive in 21 of 23 formalin-fixed paraffin-embedded sections and was negative or noncontributive in 9 of 12 frozen tissue sections, thus suggesting protein degradation on frozen storage of either sections or blocks. Indeed, a positive signal was observed in three cases of recently fresh-frozen material.

FISH analysis for the $t(11 ; 14)(q 13 ; q 32)$ detection was performed using the LSI IGH/CCND1 Dual Color, Dual Fusion Translocation Probe independently of the tissue origin, even on skin or other epithelial tissues. Analysis of signals per nuclei was possible on areas with adequately separated cells (Fig. 1G) and allowed the determination of the FISH patterns in normal nuclei (2R2G, Fig. $1 \mathrm{H})$ and in the nuclei containing the $t(11 ; 14)$ (1R1G2F, Fig. 1I). Touch preparations were more easily interpretable because they involved better separation of the nuclei. Paraffin sections sometimes showed a fluorescent background. However, they were always directly interpret- able on the microscope without numerical signal amplification. The FISH analysis demonstrated the $\mathrm{t}(11$; 14) in 34/35 MCL (Table 1). Only one case was classified as noncontributive because the biopsy specimen was small and crushed. However, cyclin D1 immunoreactivity was interpreted as positive in this case. The percentage of positive cells was variable, but each was much higher than the probe's cutoff $(5 \%)$, thus allowing an easy interpretation of either fixed or frozen tissue samples. Moreover, the three blastoid variants of MCL exhibited a complex xRyGzF $(x \neq y, z$ $\geq 2$ ) hybridization pattern (Fig. 1K). This pattern was therefore interpreted as a recurrent amplification of $C C N D 1$ and/or $I G H$ genes in addition to the $t(11 ; 14)$ in blastoid MCL variants.

The detection of the $t(11 ; 14)$ breakpoint was also performed using DNA PCR analysis on either paraffin-embedded (6) or frozen tissues (29). Using MCL1/JH primers, a t $(11 ; 14)$ breakpoint amplification was visualized and hybridized as a specific band of approximatively 500 bp (Fig. 3A). Finally, genomic PCR demonstrated a $\mathrm{t}(11 ; 14)$ breakpoint amplification in 13/35 MCL (Table 1).

Because cyclin D1 expression has been described in normal epithelial tissues (33), epithelial samples $(8 / 35)$ were not analyzed by competitive RT-PCR. This analysis was performed on frozen lymphoid samples (27/35 MCL). Cyclin D1 transcript overexpression was detected when the cyclin D1 cDNA fragment ( $482 \mathrm{bp}$ ) was found to dominate those of cyclin D2 (353 bp) and cyclin D3 (243 bp; Fig. 3B). Interestingly, the cyclin D1 transcript overexpression was evidenced in 27/27 cases (Table 1).

6 The comparison among IHC, FISH, PCR, and RTPCR analyses is shown in Figure 4. The sensitivity rates of IHC, FISH, and PCR, performed on all samples, were 69,97 , and $37 \%$, respectively. The $t(11$; 14) breakpoint amplification by PCR was positive in less than half of the MCL, although $t(11 ; 14)$ was demonstrated by FISH in $97 \%$ of the same cases. Competitive RT-PCR was only applicable to the study of nonepithelial tissues. It was positive in all tested MCLs, showing a higher sensitivity for the detection of cyclin D1 transcript overexpression than IHC, which allowed the detection of cyclin D1 protein immunoreactivity in $69 \%$ of MCL. However, IHC was applicable to all specimens.

\section{DISCUSSION}

The differentiation of MCL from other nonHodgkin's lymphomas of peripheral B-cell type is clinically relevant because patients with MCL usually present a disseminated disease, extranodal involvement, aggressive course, and refractoriness to standard chemotherapy (5). The diagnosis of MCL first relies on morphological and phenotypical cri- 

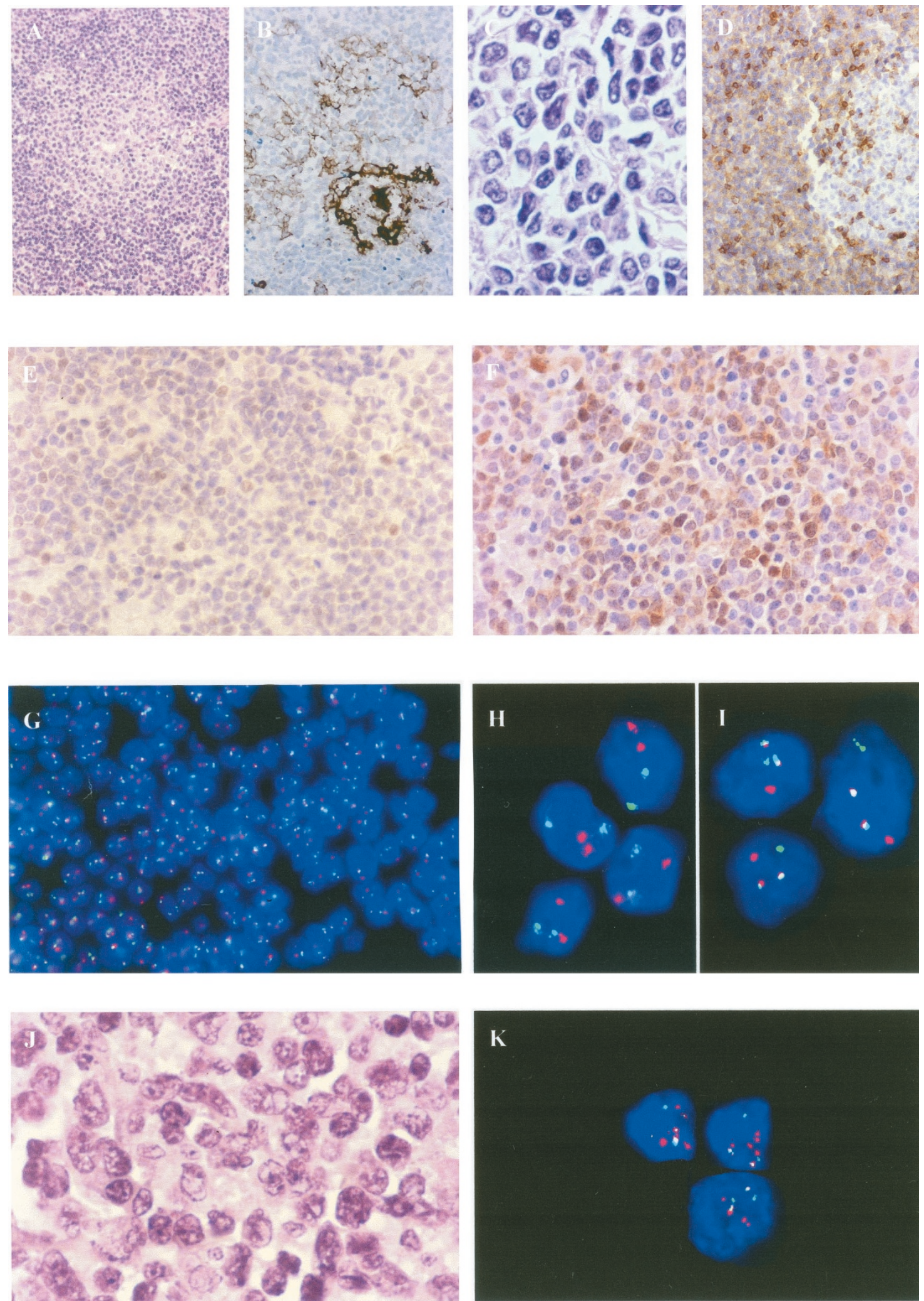

FIGURE 1. Morphological, phenotypic and cytogenetic features of mantle cell lymphoma (MCL). A, classic MCL with centrocytic cells surrounding an atrophic follicle (lymph node section, HES, 200×). B, CD23 labeling of an uneven meshwork of dendritic cells and negativity of centrocytic cells (lymph node section, immunoperoxidase, 200×). C, monotonous population of small centrocytic cells with irregular cleaved nuclei and scant cytoplasm (lymph node section, HES, $1000 \times$ ). D, CD5 labeling of both reactive T cells (strong signal) and neoplastic centrocytic cells (moderate signal); centrofollicular cells are not labeled (lymph node section, immunoperoxidase, $200 \times$ ). E and F, examples of low $(+)$ and strong $(+++)$ labeling for cyclin D1 protein (lymph node section, immunoperoxidase, $400 \times$ ). G, detection of $\mathrm{t}(11 ; 14)$ by interphase fluorescence in situ hybridization (FISH) in areas of adequately separated cells (lymph node section, $400 \times$ ). $\mathbf{H}$ and $\mathbf{I}$, examples of FISH patterns in normal nuclei (H; 2 reds, 2 green signals) and in $t(11 ; 14)+(\mathbf{I} ; 1$ red, 1 green and 2 yellow fusion signals; lymph node section, 1000 $\times$ ). J, blastoid variant of MCL characterized by larger lymphoid cells with round nuclear contours, vesicular chromatin, and some nucleoli (lymph node section, HES, $1000 \times$ ). K, examples of $C C N D 1$ amplification (red signals) in addition to $t(11 ; 14)$ fusion signals in blastoid cell nuclei after FISH analysis (lymph node section, $1000 \times)$. Note the presence of the different number of red and green signals. 
TABLE 1. Detection of $t(11 ; 14)$ (by FISH, PCR), Cyclin D1mRNA (by RT-PCR) and Protein (Immunohistochemistry) Overexpression in MCL

\begin{tabular}{lcccc}
\hline \multicolumn{1}{c}{ Test } & Pos $(n)$ & $\begin{array}{c}\text { Neg/NC } \\
(n)\end{array}$ & ND $(n)$ & $\begin{array}{c}\text { Total Cases } \\
(n)\end{array}$ \\
\hline FISH & 34 & 1 & 0 & 35 \\
RT-PCR & 27 & 0 & 8 & 35 \\
PCR & 13 & 22 & 0 & 35 \\
Immunohistochemistry & 24 & 11 & 0 & 35 \\
\hline
\end{tabular}

FISH, fluorescence in situ hybridization; PCR, polymerase chain reaction; RT-PCR, reverse transcriptase PCR; MCL, mantle cell lymphoma; Pos, positive cases; Neg, negative cases; ND, not done; NC, noncontributive.

teria but may be problematic when these features overlap with other B-cell lymphomas $(6-8)$. Therefore, the direct or indirect detection of $t(11 ; 14)$, the cytogenetic hallmark of MCL, has been progressively included among diagnostic criteria $(7,8,15$, $16,18,28,29)$. The $t(11 ; 14)$ can be directly visualized by conventional cytogenetics or interphase FISH. Molecular techniques may amplify $\mathrm{t}(11 ; 14)$ breakpoints or detect the deregulated overexpression of cyclin D1/CCND1 transcripts. Cyclin D1 immunoreactivity can be visualized on paraffin sections. As $\mathrm{t}(11 ; 14)$ may be seen in other B-cell lymphomas, the results of the above techniques have to be interpreted together with cytological and phenotypic data. So far, methods allowing the demonstration of $\mathrm{t}(11 ; 14)$ at the cytogenetic, molecular, or
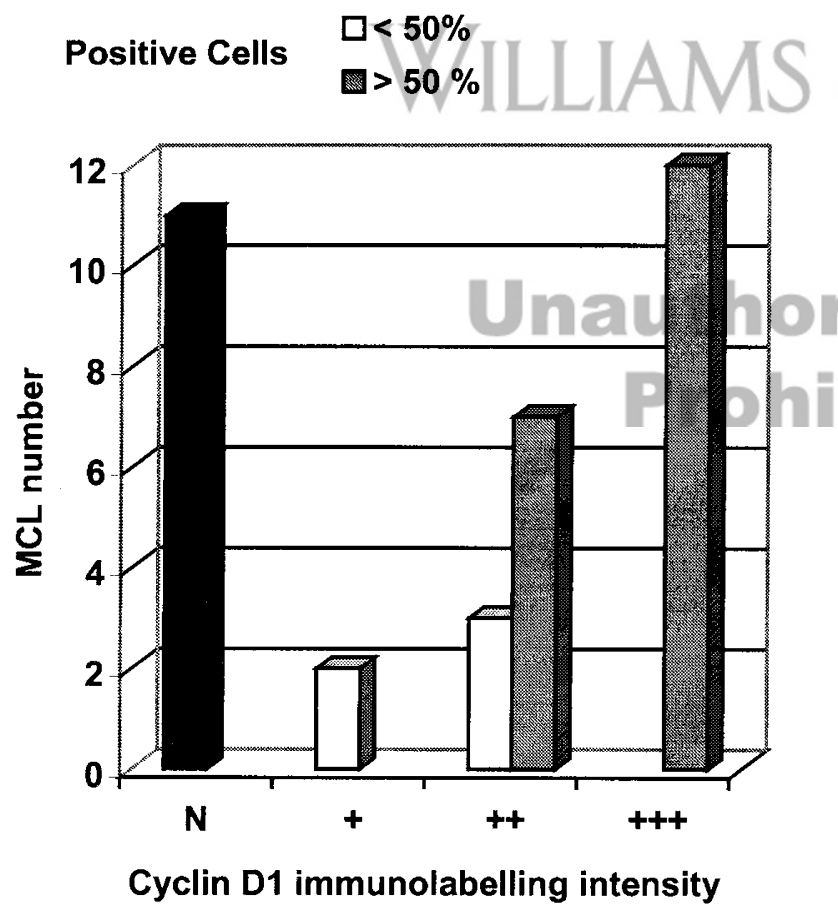

FIGURE 2. Patterns for cyclin D1 immunohistochemistry in mantle cell lymphoma (MCL). The cyclin D1 immunolabeling was evaluated for its intensity as low $(+)$, medium $(++)$, or high $(+++)$. These parameters were represented for MCL with more (gray squares) or less (white squares) than $50 \%$ of labeled cells. The remaining cases were classified as negative or as noncontributive ( $\mathrm{N}$, black squares).
A
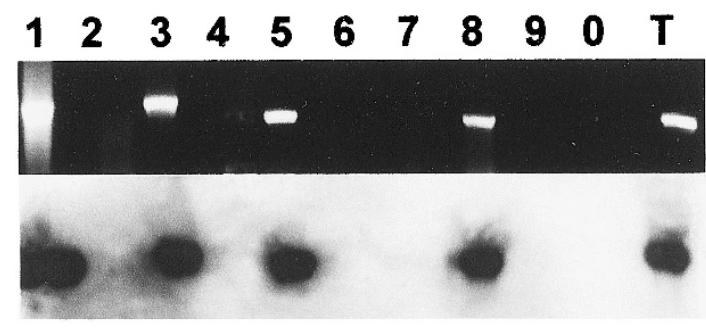

B

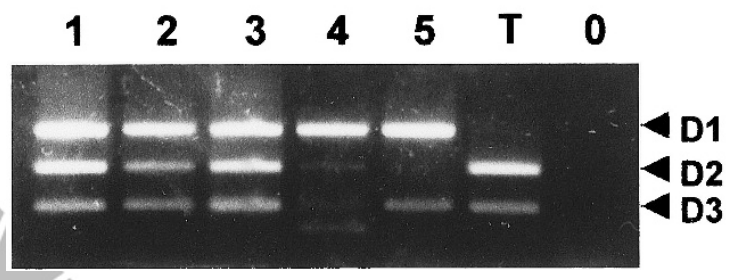

FIGURE 3. Polymerase chain reaction (PCR) and reverse transcription PCR (RT-PCR) analysis of mantle cell lymphoma (MCL). A, detection of the $t(11 ; 14)$ by PCR. Ethidium bromide staining after electrophoresis of PCR fragment (upper lane) and Southern blot hybridization with the internal digoxigenin-labeled MCL2 primer (lower lane). Lanes 1 to 9 corresponded to MCL; Lane 0, no template; Lane T, Rec1 cell line. For MCL Cases 1, 3, 5, and 8, a specific band around 500 bp was amplified using MCL1/JH primers, whereas no amplicon was detected in Cases 2, 4, 6, 7 and 9. B, competitive RT-PCR for detection of cyclin D1 transcripts overexpression. Ethidium bromide staining after electrophoresis of RT-PCR products. A 482-bp band corresponding to cyclin D1 cDNA was found to predominate over cyclin D2 (353 bp) and cyclin D3 (243 bp) bands in all MCL (Lanes 1 to 5). Lane 6, follicular

lymphoma; Lane 0 , no template.

proteic levels have not been simultaneously evaluated for their sensibility and applicability in a series of MCL cases exhibiting a typical CD5+, CD20+, CD10-,CD 23-phenotype.

Because of the difficulty in obtaining analyzable metaphase spreads, the sensitivity of FISH analysis exceeds that of chromosome analysis $(28,34,35)$. Interphase FISH has been applied for the detection of $t(11 ; 14)$, either on cell suspensions or on isolated nuclei from paraffin-embedded tissues with a $100 \%$ sensitivity $(8,29)$. Despite these encouraging results, the detection of $t(11 ; 14)$ by FISH was not found possible on paraffin sections $(8,29)$. Interphase FISH has been therefore considered a laborious technique requiring nuclei isolation (4). However, interphase FISH was employed for the detection of other chromosome abnormalities, such as Her-2/neu amplification in breast cancer (36). Our FISH assay was applied to a wide range of routine specimens, including fresh-frozen tissue touch preparations or paraffin sections. Its sensitivity $(97 \%)$ was analogous to those of previously described FISH assays on isolated nuclei $(8,29)$. It also 


\section{口NA \\ Neg/NC \\ 口Pos}

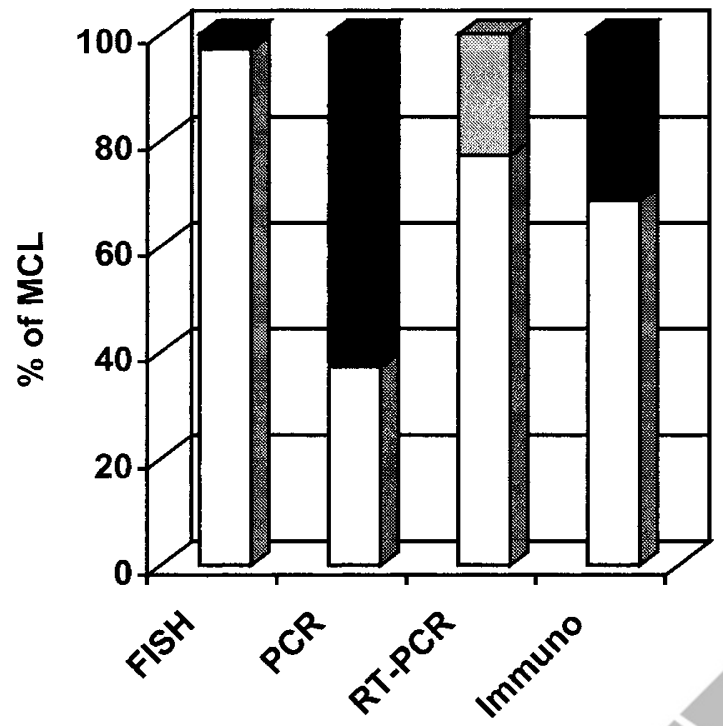

FIGURE 4. Comparative results for immunohistochemistry (cyclin D1 protein), reverse transcription polymerase chain reaction (cyclin D1 mRNA), polymerase chain reaction [t(11;14)], and FISH $[\mathrm{t}(11 ; 14)]$ analysis in mantle cell lymphoma. White squares: positive cases. Black squares: negative and/or noncontributive cases (N). Gray squares: not applicable (NA).

allowed the correlation between morphological features and cytogenetic data by targeting areas of interest after HES coloration of an adjacent tissue section. Finally, touch preparations providing a better separation of the nuclei and a lower fluorescent background could be preferred over frozen or paraffin sections for specimens containing numerous lymphoma cells, but touch preparations do not permit checking of which area or cells are analyzed in cases with partial infiltration. Moreover, their conservation on long-term storage was not evaluated.

Moreover, FISH evidenced a CCND1 amplification in the three blastoid MCLs of our series. Such amplification was recently demonstrated in blastoid variants of MCL by a dual-color FISH assay using CCND1 and centromeric chromosome 11 probes (37). Such amplification was interpreted as the result of tetraploid chromosomes 11 because tetraploid chromosome clones already had been identified in $80 \%$ of blastoid MCLs $(37,38)$. In the present study, the powerful combination of CCND1 and IGH probes gave additional information. First, it allowed the detection of CCND1 amplification and $t(11 ; 14)$ in the same nuclei. Second, in nuclei with CCND1 amplification, we observed an imbalance between the number of red signals (CCND1) and green signals $(I G H)$, with, in some nuclei, more than four red signals. Thus, CCND1 amplification in blastoid MCL may also result from another mech- anism than tetraploidy. As karyotype data may be absent, as for our patients, the identification of CCND1 amplification by interphase FISH may allow us to identify blastoid variants of MCL that may have a more aggressive course (39).

The amplification of $\mathrm{t}(11 ; 14)$ breakpoints by DNA-PCR is hampered by the scattering of 11 q13 breakpoints $(23,25,26)$. The poor sensitivity $(37 \%)$ obtained in our study falls in the range of previous reports $(25,26)$. Such technique cannot therefore be considered an efficient tool for initial diagnosis but remains of potential use for monitoring minimal residual disease in positive cases, especially by quantitative PCR (40).

At the RNA level, cyclin D1 transcripts have been detected in MCL, in non-MCL B-cell lymphomas, as well as in certain normal tissues $(4,7,16)$. Therefore, quantitative or semiquantitative RT-PCR assays are required to demonstrate cyclin D1 transcript overexpression in MCLs $(4,7,41,42)$. The competitive RTPCR assay using cyclin D2 and D3 transcripts as internal controls (16) was not found suitable for the study of epithelial tissues, such as skin or digestive tract specimens, which normally express cyclin D1 (33). By excluding such samples (8/35), cyclin D1 transcript overexpression was observed in all tested cases, which is in accordance with the 89 to $100 \%$ sensitivity rates described by other investigators $(4,7$, 42). Cyclin D1 transcripts can also be detected and localized to MCL cells on paraffin sections by in situ hybridization (ISH) with a $86 \%$ sensitivity $(4,17)$. However, ISH is not a quantitative technique, and its reproducibility remains to be evaluated.

$\checkmark$ IHC for cyclin D1 was applied in our study whatever the tissue origin, both on frozen or paraffinembedded sections. Our sensitivity rate (69\%) falls into the range of previously described rates of cyclin D1 immunodetection of from 69 to $100 \%$ (4, 6, 7, 18). High variations in labeling intensity have been observed, as in our study. These variabilities may be related to difficulties in finding a reliable method for cyclin D1 immunostaining $(6,43)$. The different rates observed for frozen (25\%) or paraffin sections (91\%) also suggest that cyclin D1 immunodetection requires a rapid fixation procedure with formalin which, in turn, may increase IHC sensitivity.

In conclusion, comparative studies of some of these techniques have shown that semiquantitative RT-PCR and/or ISH had a better sensitivity than IHC for the diagnosis of MCL $(4,7)$. Despite a lower sensitivity, cyclin D1 IHC can be considered a simple, cost-effective, and reliable routine technique that should be performed in the diagnosis of lymphomas with MCL-evoking morphology and phenotype. However, negative cases may remain problematic because of possible artifacts. Therefore, our study emphasizes the use of FISH analysis for the direct detection of $t(11 ; 14)$ in such samples because 
the combination of its applicability and sensibility largely exceeded those of other techniques. It may also provide some information on secondary cytogenetic changes of potential clinical relevance.

Acknowledgments: The authors thank Michelle Turmo, Françoise Boiteau, and Christine Bartoli for technical support.

\section{REFERENCES}

1. Weisenburger DD, Armitage JO. Mantle cell lymphoma-an entity comes of age. Blood 1996;87:4483-94.

2. Harris NL, Jaffe ES, Stein H, Banks PM, Chan JK, Cleary ML, et al. A revised European-American classification of lymphoid neoplasms: a proposal from the International Lymphoma Study Group. Blood 1994;84:1361-92.

3. Harris NL, Jaffe ES, Diebold J, Flandrin G, Muller-Hermelink HK, Vardiman J, et al. World Health Organization classification of neoplastic diseases of the hematopoietic and lymphoid tissues: report of the Clinical Advisory Committee meeting-Airlie House, Virginia, November 1997. J Clin Oncol 1999;17:3835-49.

4. Athanasiou E, Kotoula V, Hytiroglou P, Kouidou S, Kaloutsi V, Papadimitriou CS. In situ hybridization and reverse transcription-polymerase chain reaction for cyclin D1 mRNA in the diagnosis of mantle cell lymphoma in paraffinembedded tissues. Mod Pathol 2001;14:62-71.

5. Samaha H, Dumontet C, Ketterer N, Moullet I, Thieblemont C, Bouafia F, et al. Mantle cell lymphoma: a retrospective study of 121 cases. Leukemia 1998;12:1281-7.

6. Kurtin PJ, Hobday KS, Ziesmer S, Caron BL. Demonstration of distinct antigenic profiles of small B-cell lymphomas by paraffin section immunohistochemistry. Am J Clin Pathol 1999;112:319-29.

7. Aguilera NS, Bijwaard KE, Duncan B, Krafft AE, Chu WS, Abbondanzo SL, et al. Differential expression of cyclin D1 in mantle cell lymphoma and other non-Hodgkin's lymphomas. Am J Pathol 1998;153:1969-76.

8. Remstein ED, Kurtin PJ, Buno I, Bailey RJ, Proffitt J, Wyatt WA, et al. Diagnostic utility of fluorescence in situ hybridization in mantle-cell lymphoma. Br J Haematol 2000;110:856-62.

9. Leroux D, Le Marc'Hadour F, Gressin R, Jacob MC, Keddari E, Monteil M, et al. Non-Hodgkin's lymphomas with t(11 14) (q13;q32): a subset of mantle zone/intermediate lymphocytic lymphoma? Br J Haematol 1991;77:346-53.

10. Raynaud SD, Bekri S, Leroux D, Grosgeorge J, Klein B, Bastard $\mathrm{C}$, et al. Expanded range of $11 \mathrm{q} 13$ breakpoints with differing patterns of cyclin D1 expression in B-cell malignancies. Genes Chromosom Cancer 1993;8:80-7.

11. Tsujimoto Y, Yunis J, Onorato-Showe L, Erikson J, Nowell PC, Croce CM. Molecular cloning of the chromosomal breakpoint of B-cell lymphomas and leukemias with the $t(11 ; 14)$ chromosome translocation. Science 1984;224:1403-6.

12. Ince C, Blick M, Lee M, Pathak S, Vadhan-Raj S, Selvanayagam $\mathrm{P}$, et al. Bcl-1 gene rearrangements in B cell lymphoma. Leukemia 1988;2:343-6.

13. Koduru PR, Offit K, Filippa DA. Molecular analysis of breaks in BCL-1 proto-oncogene in B-cell lymphomas with abnormalities of 11q13. Oncogene 1989;4:929-34.

14. Williams ME, Meeker TC, Swerdlow SH. Rearrangement of the chromosome 11 bcl-1 locus in centrocytic lymphoma: analysis with multiple breakpoint probes. Blood 1991;78:493-8.

15. Rimokh R, Berger F, Delsol G, Charrin C, Bertheas MF, Ffrench $\mathrm{M}$, et al. Rearrangement and overexpression of the BCL-1/ PRAD-1 gene in intermediate lymphocytic lymphomas and in t(11q13)-bearing leukemias. Blood 1993;81:3063-7.
16. Uchimaru K, Taniguchi T, Yoshikawa M, Asano S, Arnold A, Fujita T, et al. Detection of cyclin D1 (bcl-1, PRAD1) overexpression by a simple competitive reverse transcriptionpolymerase chain reaction assay in $\mathrm{t}(11 ; 14)(\mathrm{q} 13 ; \mathrm{q} 32)-$ bearing B-cell malignancies and/or mantle cell lymphoma. Blood 1997;89:965-74.

17. Williams ME, Nichols GE, Swerdlow SH, Stoler MH. In situ hybridization detection of cyclin D1 mRNA in centrocytic/ mantle cell lymphoma. Ann Oncol 1995;6:297-9.

18. de Boer CJ, Schuuring E, Dreef E, Peters G, Bartek J, Kluin $\mathrm{PM}$, et al. Cyclin D1 protein analysis in the diagnosis of mantle cell lymphoma. Blood 1995;86:2715-23.

19. Yang WI, Zukerberg LR, Motokura T, Arnold A, Harris NL. Cyclin D1 (Bcl-1, PRAD1) protein expression in low-grade B-cell lymphomas and reactive hyperplasia. Am J Pathol 1994; 145:86-96.

20. Sherr CJ. Mammalian G1 cyclins. Cell 1993;73:1059-65.

21. Komatsu H, Yoshida K, Seto M, Iida S, Aikawa T, Ueda R, et al. Overexpression of PRAD1 in a mantle zone lymphoma patient with a $\mathrm{t}(11 ; 22)(\mathrm{q} 13 ; \mathrm{q} 11)$ translocation. Br J Haematol 1993;85:427-9.

22. de Boer CJ, Vaandrager JW, van Krieken JH, Holmes Z, Kluin PM, Schuuring E. Visualization of mono-allelic chromosomal aberrations $3^{\prime}$ and 5' of the cyclin D1 gene in mantle cell lymphoma using DNA fiber fluorescence in situ hybridization. Oncogene 1997;15:1599-603.

23. de Boer CJ, Loyson S, Kluin PM, Kluin-Nelemans HC, Schuuring E, van Krieken JH. Multiple breakpoints within the BCL-1 locus in B-cell lymphoma: rearrangements of the cyclin D1 gene. Cancer Res 1993;53:4148-52.

24. Luthra R, Hai S, Pugh WC. Polymerase chain reaction detection of the $t(11 ; 14)$ translocation involving the bcl-1 major translocation cluster in mantle cell lymphoma. Diagn Mol Pathol 1995;4:4-7.

25. Molot RJ,' Meeker TC, Wittwer CT, Perkins SL, Segal GH, Masih AS, et al. Antigen expression and polymerase chain reaction amplification of mantle cell lymphomas. Blood 1994;83:1626-31.

26. Rimokh R, Berger F, Delsol G, Digonnet I, Rouault JP, Tigaud JD, et al. Detection of the chromosomal translocation $\mathrm{t}(11$; 14) by polymerase chain reaction in mantle cell lymphomas. Blood 1994;83:1871-5.

27. Vandenberghe E, De Wolf Peeters C, Wlodarska I, Stul M, Louwagie A, Verhoef G, et al. Chromosome 11q rearrangements in B non Hodgkin's lymphoma. Br J Haematol 1992;81:212-7.

28. Avet-Loiseau H, Garand R, Gaillard F, Daviet A, Mellerin MP, Robillard N, et al. Detection of $\mathrm{t}(11 ; 14)$ using interphase molecular cytogenetics in mantle cell lymphoma and atypical chronic lymphocytic leukemia. Genes Chromosom Cancer 1998;23:175-82.

29. Li JY, Gaillard F, Moreau A, Harousseau JL, Laboisse C, Milpied N, et al. Detection of translocation $\mathrm{t}(11 ; 14)$ (q13;q32) in mantle cell lymphoma by fluorescence in situ hybridization. Am J Pathol 1999;154:1449-52.

30. Macintyre EA, Willerford D, Morris SW. Non-Hodgkin's lymphoma. Molecular features of B cell lymphoma. Hematology 2000;180-204.

31. Troussard X, Mauvieux L, Radford-Weiss I, Rack K, Valensi F, Garand R, et al. Genetic analysis of splenic lymphoma with villous lymphocytes: a Groupe Francais d'Hematologie Cellulaire (GFHC) study. Br J Haematol 1998;101:712-21.

32. Miranda RN, Briggs RC, Kinney MC, Veno PA, Hammer RD, Cousar JB. Immunohistochemical detection of cyclin D1 using optimized conditions is highly specific for mantle cell lymphoma and hairy cell leukemia. Mod Pathol 2000;13:1308-14.

33. Bartkova J, Lukas J, Strauss M, Bartek J. Cell cycle-related variation and tissue-restricted expression of human cyclin D1 protein. J Pathol 1994;172:237-45. 
34. Zucca E, Soldati G, Schlegelberger B, Booth MJ, WeberMatthiesen K, Cavalli F, Cotter FE. Detection of chromosome 11 alterations in blood and bone marrow by interphase cytogenetics in mantle cell lymphoma. Br J Haematol 1995;89:665-8.

35. Siebert R, Matthiesen P, Harder S, Zhang Y, Borowski A, Zuhlke-Jenisch R, et al. Application of interphase cytogenetics for the detection of $t(11 ; 14)(q 13 ; q 32)$ in mantle cell lymphomas. Ann Oncol 1998;9:519-26.

36. Moore JG, To V, Patel SJ, Sneige N. HER-2/neu gene amplification in breast imprint cytology analyzed by fluorescence in situ hybridization: direct comparison with companion tissue sections. Diagn Cytopathol 2000;23:299-302.

37. Katz RL, Caraway NP, Gu J, Jiang F, Pasco-Miller LA, Glassman $\mathrm{AB}$, et al. Detection of chromosome 11q13 breakpoints by interphase fluorescence in situ hybridization. A useful ancillary method for the diagnosis of mantle cell lymphoma. Am J Clin Pathol 2000;114:248-57.

38. Ott G, Kalla J, Ott MM, Schryen B, Katzenberger T, Muller JG, et al. Blastoid variants of mantle cell lymphoma: frequent bcl-1 rearrangements at the major translocation cluster region and tetraploid chromosome clones. Blood 1997;89:1421-9.
39. Argatoff LH, Connors JM, Klasa RJ, Horsman DE, Gascoyne RD. Mantle cell lymphoma: a clinicopathologic study of 80 cases. Blood 1997;89:2067-78.

40. Luthra R, Sarris AH, Hai S, Paladugu AV, Romaguera JE, Cabanillas FF, et al. Real-time 5'-more than 3' exonucleasebased PCR. assay for detection of the $\mathrm{t}(11 ; 14)(\mathrm{q} 13 ; \mathrm{q} 32)$. Am J Clin Pathol 1999;112:524-30.

41. Bijwaard KE, Aguilera NS, Monczak Y, Trudel M, Taubenberger JK, Lichy JH. Quantitative real-time reverse transcription-PCR assay for cyclin D1 expression: utility in the diagnosis of mantle cell lymphoma. Clin Chem 2001;47:195-201.

42. Suzuki R, Takemura K, Tsutsumi M, Nakamura S, Hamajima N, Seto M. Detection of cyclin d1 overexpression by realtime reverse-transcriptase-mediated quantitative polymerase chain reaction for the diagnosis of mantle cell lymphoma. Am J Pathol 2001;159:425-9.

43. Korin HW, Schwartz MR, Chirala M, Younes M. Optimized cyclin D1 immunoperoxidase staining in mantle cell lymphoma. Appl Immunohistochem Mol Morphol 2000;8:5760

\section{Book Review}

\section{Ramzy l: Clinical Cytopathology and Aspiration Biopsy, Fundamental Principles and Prac- tice, 2nd Edition, 619 pp, New York, McGraw-Hill, 2001 (\$199.00).}

The growth of diagnostic cytopathology during the past two decades has lead to a plethora of books trying to meet the growing demand. It is easy to predict that most of these books will be forgotten soon and will never have a second edition. Those that survive in the overcrowded and highly competitive, but limited, market will do so only on their own merit and only because they have something that makes them unique and different from all others that have the same (or more or less similar) title.

The first edition of Dr. Ramzi's book appeared in 1990 and was favorably accepted. The fact that a second edition was commissioned indicates that the book was selling and that the readers liked it-there is still nothing like word-of-mouth recommendation from one user to another! For this reviewer, only marginally related to cytopathology, it is thus a challenge to figure out what makes this book so special as to justify a second edition.

My answers to this challenge are as follows: first of all, in 1990 this book was one of the pioneering efforts to explain the intricacies of cytopathology to pathologists in training and make it understandable (as well as acceptable) to old-timers with classical histopathologic backgrounds. Once the formula for a good book was discovered, it obviously took less time and effort to update it than to start from scratch. In this context it is worth mentioning that the original book was thoroughly revised and fully updated.
Second, the book is true to its title: it deals with and masterfully presents the fundamental principles of cytopathology and shows how to use those principles in practice. Third, the author and his associates use histopathology as the springboard from which they interpret the cytologic manifestations of various diseases. In the same vein, tissue diagnosis is constantly used for final validation of its cytopathologic equivalent. Fourth, the book is just the right size-neither too big nor too small. The buyer has the feeling that he or she can read it in a reasonable period of time, such as a 2-month rotation in cytology. Fifth, the text, written in straightforward expository no-nonsense prose, is very readable. The didactic value of the well-chosen, high-quality color photographs used for the cytologichistopathologic correlations cannot be overemphasized. The tables summarizing the differential diagnostic points are well done and designed for practicing pathologists. Finally, it helps that the book is printed on high-quality paper and nicely designed. I am confident that the book will appeal to residents as well as practicing pathologists, but above all to instructors trying to introduce the principles of cytopathology to their students and show how this subspecialty of pathology is linked to other forms of microscopic and clinical diagnosis.

\section{Ivan Damjanov \\ University of Kansas School of Medicine \\ Kansas City, Kansas}

